\title{
Pharmacological action of tick saliva upon haemostasis and the neutralization ability of sera from repeatedly infested hosts
}

\author{
J. RECK Jr. ${ }^{1}$, M. BERGER ${ }^{1}$, F. S. MARKS ${ }^{2}$, R. B. ZINGALI ${ }^{3}$, C. W. CANAL ${ }^{2}$, \\ C. A. S. FERREIRA ${ }^{4}$, J. A. GUIMARÃES ${ }^{1}$ and C. TERMIGNONI I ${ }^{1,5 *}$ \\ ${ }^{1}$ Centro de Biotecnologia, Universidade Federal do Rio Grande do Sul (UFRGS), Porto Alegre - RS - Brazil \\ ${ }^{2}$ Departamento de Patologia Clínica Veterinária, Faculdade de Veterinária, Universidade Federal do Rio Grande do Sul \\ (UFRGS), Porto Alegre - RS - Brazil \\ ${ }^{3}$ Instituto de Bioquímica Médica, Universidade Federal do Rio de Faneiro (UFRF), Rio de Faneiro - RF - Brazil \\ ${ }^{4}$ Departamento de Biologia Celular e Molecular, Faculdade de Biociências, Pontifícia Universidade Católica do Rio Grande do \\ Sul (PUCRS), Porto Alegre - RS - Brazil \\ ${ }^{5}$ Departamento de Bioquímica, Instituto de Ciências Básicas da Saúde (ICBS), Universidade Federal do Rio Grande do Sul \\ (UFRGS), Porto Alegre - RS - Brazil
}

(Received 4 May 2009; revised 24 May 2009; accepted 26 May 2009; first published online 23 Fuly 2009)

\section{S U MMAR Y}

Ticks are blood-feeding arthropods widely distributed in the world and vectors of several diseases. As haematophagy demands evasion strategies and repeatedly infested hosts develop protective immune responses, we investigated the mechanisms of the Rhipicephalus (Boophilus) microplus saliva anti-haemostatic activity and the possible relationship between the acquired natural anti-tick host resistance and anti-haemostatic action. For this purpose, we studied the effects of R. microplus saliva on different pathways of haemostasis and tested whether repeated infested bovine sera (RIBS) are able to abolish salivary anti-haemostatic activities. $R$. microplus saliva (i) displays inhibitory activity upon collagen-induced platelet aggregation; (ii) inhibits the induction of endothelial pro-coagulant state; and (iii) reduces thrombogenesis in vivo. RIBS were shown to be able to partially block the delay of coagulation and the anti-thrombotic effect of saliva, and to totally abolish the modulation of endothelium activation. Conversely, RIBS has no effect on the inhibition of platelet aggregation. These results show, for the first time, the neutralization ability of sera from acquired resistance hosts against tick antihaemostatics. Moreover, this is the first report of a haematophagous parasite able to modulate endothelial cell procoagulant state, and addresses the presence of anti-platelet and anti-thrombotic activity in $R$. microplus saliva.

Key words: Rhipicephalus (Boophilus) microplus, tick, haematophagous, haemostasis, coagulation, platelet, endothelium, thrombosis, bovine resistance.

\section{INTRODUCTION}

Ticks are blood-feeding arthropods widely distributed in the world, which are able to parasitize humans as well as almost any domestic and wildlife vertebrate animals. In several countries, ticks are important public health hazards, since these arthropods are vectors of several bacterial, viral and protozoan tick-borne diseases (Walker, 1998).

Once a tick has found a host and reaches the attachment site, it introduces its mouthparts into the skin and induces vessel damage, which in turn triggers mechanisms to avoid blood loss and infection such as vasoconstriction, platelet aggregation,

* Corresponding author: Centro de Biotecnologia, Universidade Federal do Rio Grande do Sul (UFRGS), Av. Bento Gonçalves, 9500, P.O. Box 15005, ZIP Code 91501-970, Porto Alegre, RS, Brazil. Tel: + 5551 33086082.Fax +55 51 33087309. E-mail: ctermignoni@ cbiot.ufrgs.br. coagulation, inflammation and migration of immune cells to the lesion site (Simmonds and Lane, 1998). Therefore, it could be stated that a successful bloodmeal depends on a fine balance between the pharmacological action of tick saliva and host responses. Thus, tick salivary secretion plays a major role in the modulation of host haemostatic and immunological responses (Ribeiro, 1989, 1995 ; MaritzOlivier et al. 2007).

Several molecules with a large range of pharmacological properties have been characterized in tick saliva (for comprehensive reviews see Champagne and Valenzuela, 1996; Ribeiro and Francischetti, 2003; Francischetti et al. 2009). These molecules may act as vasodilators (Dickinson et al. 1976; Kemp et al. 1983), anti-platelets (Mans et al. 1998, 2002; Mans and Ribeiro, 2008), anti-coagulants (Horn et al. 2000; Francischetti et al. 2002, 2004; Ciprandi et al. 2006), immunosuppressants (Juncadella et al. 2007; Konnai et al. 2009) and anti-inflammatories (Kotsyfakis et al. 2006; Déruaz et al. 2008). Recently, 
we conducted an in vivo study reporting the systemic modulation of haemostasis from tick-naïve bovines infested with Rhipicephalus (Boophilus) microplus (Reck Jr et al. 2009). The study has shown that the consequences of the biological action of tick saliva to the host may be much more far-reaching than initially suspected, and that little is known about the full impact of these compounds to the tick-host relationship.

On the other hand, a well-known phenomenon occurs after repeated tick infestations: host acquisition of resistance (Wikel and Whelen, 1986), which seems to be mediated mainly by immune responses (Allen, 1994). Although this resistance status was widely studied and is mostly related to cellular immune responses, namely mediated by basophils and eosinophils, (Wikel et al. 1996), it also seems to depend on serum neutralization ability against several tick molecules, and the role of these tick compounds targeted by host serum requires further investigation.

The cattle tick R. microplus, formerly Boophilus microplus (Murrel and Barker, 2003), is the most harmful bovine parasite in Latin America and Australia (Jongejan and Uilenberg, 2004). R. microplus is also a consistent model to study the tick-host relationship, since it remains attached to the same host throughout the whole parasitic stage, which lasts around 3 weeks (Guimarães et al. 2001). Until now, thrombin inhibition was the only identified pathway of anti-haemostatic activity in $R$. microplus, since the anti-haemostatics reported for $R$. microplus were 2 thrombin inhibitors in saliva (Horn et al. 2000; Ciprandi et al. 2006), and 1 thrombin inhibitor in the gut (Ricci et al. 2007). Yet, no information has been made available about the pharmacological activity of $R$. microplus salivary compounds upon platelets, endothelium and in vivo models of thrombogenesis.

The aims of this work were to identify and to explore the pharmacological mechanisms of R. microplus saliva anti-haemostatic activity and to investigate a possible relationship between the acquired natural tick resistance and the anti-haemostatic action of this tick. For this purpose, we have studied the effects of $R$. microplus saliva on platelet aggregation, endothelial activation and thrombogenesis. We have also investigated whether sera from acquired natural tick resistance cattle were able to counteract the antihaemostatic action of tick saliva.

\section{MATERIALS AND METHODS}

\section{Animals}

Three male Hereford calves (Bos taurus taurus) of about 6 months of age from a tick-free area were utilized in this work. All procedures involving bovines were carried out in accordance with the
Guide for the Care and Use of Agricultural Animals in Agricultural Research and Teaching (FASS, 1999). Male Wistar rats (weighing 350-400 g) and male New Zealand rabbits $(3 \cdot 5-4 \mathrm{~kg})$ were also used in this work, and were housed in temperaturecontrolled $\left(21-24{ }^{\circ} \mathrm{C}\right.$, in 12-h light/dark cycles) rooms. All animals had access to water and food ad libitum. All experiments performed in this work were carried out in accordance with local institutional ethical guidelines about animal experimentation, and all procedures were also in accordance with the instructions of the Colégio Brasileiro de Experimentação Animal (COBEA) and NIH Animal Care Guidelines. Every effort was made to minimize the number of animals used and their suffering.

\section{Drugs and reagents}

Human plasma was obtained from 6 healthy male medication-free volunteers; bovine plasma was obtained from 3 tick-naïve male Hereford calves; all plasma samples were collected in $3 \cdot 2 \%$ sodium citrate $(1: 10, \mathrm{v} / \mathrm{v})$. Human thrombin was purified in our laboratory from plasma of healthy donors according to the method of Ngai and Chang (1991). Arachidonic acid was obtained and prepared following the instructions of manufacturer (ChronoLog Co., Havertown, USA). Bovine collagen type I; adenosine diphosphate (ADP); bovine fibrinogen, lipopolysaccharide (LPS, Escherichia coli 0111:B4, cell culture tested, $\gamma$-irradiated); and HAT media supplement (Hybri-Max ${ }^{\mathrm{TM}}$, lyophilized powder, $\gamma$-irradiated) were purchased from Sigma-Aldrich (St Louis, MO, USA). All other culture media and additives were from Gibco Life Technologies (Gaithersburg, USA). Calcium thromboplastin (Soluplastin) was obtained from Wiener Lab (Rosario, Argentina). Sodium thiopental was purchased from Cristália Produtos Químicos Farmacêuticos (São Paulo, Brazil).

\section{Infestation procedure and serum preparation}

The tick-naïve bovines were infested with $R$. microplus larvae as described by $\mathrm{Cruz}$ and co-workers (2008). Briefly, 6 male Bos taurus taurus Hereford calves of about 6 months of age were purchased from an area naturally free of $R$. microplus. Infestations were performed with each calf being infested once a month for 12 months with $R$. microplus larvae of the Bagé strain along the back. Serum samples collected before the 1 st infestation were called tick-naïve bovine sera (TNBS), and the serum samples collected after the 10th infestation were named as repeated infested bovine serum (RIBS). After 10 infestations, the bovines utilized to obtain RIBS displayed a significant decrease in the observed number of ticks that completed the parasitic cycle (Cruz et al. 2008). 


\section{Tick saliva}

Fully engorged $R$. microplus females that had spontaneously detached from the bovines were collected, rinsed, and induced to salivate with injection of $5 \mu \mathrm{l}$ pilocarpine $(2 \%)$. Ticks were maintained in a humid chamber and saliva was collected for $2 \mathrm{~h}$ (approximately $1 \mu \mathrm{l}$ per tick). Saliva was stored at $-80{ }^{\circ} \mathrm{C}$ until use. Saliva protein concentration was determined using the bicinchoninic acid method $\left(\mathrm{BCA}^{\mathrm{TM}}\right.$ Protein Assay, Pierce, Rockford, USA) as previously described (Brown, 1989). Saliva quantities were expressed as $\mu \mathrm{g}$ or $\mathrm{mg}$ of protein. The saliva utilized in this work was collected only from engorged females which fed on bovines never exposed to ticks before.

\section{Coagulation assay}

Plasma samples from tick-naïve bovines (100 $\mu \mathrm{l})$ were incubated for $15 \mathrm{~min}$ with phosphate-buffered saline (PBS) or tick saliva $(5 \mu \mathrm{l} ; 80 \mu \mathrm{g} / \mathrm{ml})$ previously incubated for $20 \mathrm{~min}$ with different volumes $(15,30$, 60 and $90 \mu \mathrm{l})$ of TNBS, RIBS, or PBS. Coagulation was measured by Recalcification Time (RT), performed as previously described (Ribeiro et al. 1995; Berger et al. 2008). The assay was conducted using a 96-well microplate spectrophotometer (SpectraMax, Molecular Devices Co., Sunnyvale, USA) equipped with temperature and shaking controls. Results are the mean of 12 independent experiments.

\section{Platelets}

The platelet function was measured by in vitro photometric method (Born and Cross, 1963), in an optical aggregometer (Chrono-Log Co., Havertown, USA). Blood samples were collected by punction of marginal ear artery from male New Zealand rabbits using ACD solution as anticoagulant $(2 \cdot 5 \%$ trisodium citrate, $1 \cdot 37 \%$ citric acid, $2 \% \mathrm{D}$-glucose $; 1: 5$ $\mathrm{v} / \mathrm{v}$ ). Washed rabbit platelets (WRP) were obtained as follows. Blood was centrifuged 3 times at $200 \boldsymbol{g}$ for $5 \mathrm{~min}$ to obtain platelet rich plasma (PRP). PRP was centrifuged at $650 \boldsymbol{g}$ for $10 \mathrm{~min}$. The supernatant was discarded and the platelet pellet was suspended in $300 \mu \mathrm{l}$ of ACD solution. Then, platelets were purified/washed following a protocol developed by Timmons and Hawinger (1989) consisting of gel filtration in a Sepharose-2B column equilibrated and eluted with Tyrode-albumin buffer, $\mathrm{pH} 7 \cdot 4$. Washed platelet suspensions were supplemented with $2 \mathrm{~mm}$ $\mathrm{CaCl}_{2}$ and $500 \mu \mathrm{g} / \mathrm{ml}$ of fibrinogen. The platelet count was performed manually in a Neubauer chamber (haemocytometer) using optical microscopy and the platelet concentration was adjusted to 350000 cells/ $\mu 1$. Aggregation was measured using the decrease rate in WRP $(300 \mu \mathrm{l})$ optical density (absorbance) in response to the addition of one of the following agonist agents: adenosine diphosphate (ADP) $(10 \mu \mathrm{M})$, bovine collagen type I $(40 \mu \mathrm{g} / \mathrm{ml})$, arachidonic acid $(10 \mu \mathrm{M})$, or human thrombin $(2 \cdot 5 \mathrm{U} /$ $\mathrm{ml}$ ). In order to verify whether $R$. microplus saliva was able to inhibit platelet aggregation, different concentrations of saliva were pre-incubated with platelets (for $15 \mathrm{~min}$ ) before adding the agonist. For the experiments with serum, TNBS or RIBS were previously incubated (for $20 \mathrm{~min}$ ) with $R$. microplus saliva before adding it to the platelet preparation. Results are the mean of 6 independent experiments.

\section{Cell culture}

EAhy926 is a human derived endothelial cell line originated by fusing human umbilical vein endothelial cells with the permanent cell line of human lung carcinoma, A549 (Edgell et al. 1983). EAhy926 has been used as a model to study the endothelium, since it displays conserved functional characteristics of an endothelial cell (Edgell et al. 1983). Cells were maintained in Dulbecco's modified Eagle's medium (DMEM) containing 10\% fetal calf serum (FCS), penicillin/streptomycin (200 units/ml and $200 \mu \mathrm{g} /$ $\mathrm{ml}$, respectively), and supplemented with $100 \mu \mathrm{M}$ hypoxanthine, $0 \cdot 4 \mu \mathrm{M}$ aminopterin, and $16 \mu \mathrm{M}$ thymidine (HAT media supplement), at $37^{\circ} \mathrm{C}$ in an incubator with humidified atmosphere of air $/ \mathrm{CO}_{2}$ $(95 \% / 5 \%)$. As previously described, this cell line no requires additional growth factors (Edgell et al. 1983).

\section{Cell surface-pro-coagulant assay}

Pro-coagulant activity was measured on the surface of endothelial cell monolayers (EAhy926) using a 96well microplate spectrophotometer (SpectraMax ${ }^{\circledR}$, Molecular Devices Co., Sunnyvale, USA), based on the modified one-stage clotting assay (Visseren et al. 2000), as follows. EAhy926 cells cultured in DMEM (3\% FCS) were seeded on 96-well microplates at a density of 40000 cells/well and, after $24 \mathrm{~h}$, different treatments were performed ( $\approx 80 \%$ confluence). Cells were divided into 4 groups ( 6 wells per group) and received the following treatments (a final volume of $150 \mu \mathrm{l}$ was completed with DMEM): (i) $30 \mu \mathrm{l}$ of PBS; (ii) saliva $(5 \mu \mathrm{l} ; 40 \mu \mathrm{g} / \mathrm{ml})+25 \mu \mathrm{l}$ of PBS; (iii) saliva $(40 \mu \mathrm{g} / \mathrm{ml})+25 \mu \mathrm{l}$ of RIBS; or (iv) saliva $(40 \mu \mathrm{g} / \mathrm{ml})+25 \mu \mathrm{l}$ of TNBS. After $48 \mathrm{~h}$ all groups received $150 \mu \mathrm{g} / \mathrm{ml}$ of LPS to induce endothelial activation. After $24 \mathrm{~h}$, culture medium was totally removed and cells were washed 3 times with PBS. Monolayers were incubated with $100 \mu \mathrm{l}$ of Michaelis buffer (sodium-acetate $28.5 \mathrm{~mm}$, sodium-barbital $28.5 \mathrm{~mm}, \mathrm{NaCl} 50 \mathrm{~mm}, \mathrm{CaCl}_{2} 33 \mathrm{~mm}, \mathrm{pH} 7 \cdot 35$ ) at $37^{\circ} \mathrm{C}$ for $60 \mathrm{~s}$, after which $100 \mu \mathrm{l}$ of human pooled citrated plasma was added. The endothelial 
induced-plasma clotting was measured in a spectrophotometer. The value obtained for PBS-treated group (control) was considered as having $100 \%$ procoagulant activity. Results are the mean of 8 independent experiments. Additional experiments $(n=3)$, using neutral red based cytotoxicity assay (TOX- $4{ }^{\circledR}$ in vitro toxicology assay kit, SigmaAldrich, St Louis, MO, USA), were performed to evaluate the cell viability after the different treatments.

\section{In vivo model of deep venous thrombosis}

For the determination of anti-thrombotic saliva activity, a rat thrombosis model was performed. The model is a combination of stasis and hypercoagulability induced by the injection of an exogenous tissue factor-rich component, as previously described (Vogel et al. 1989; Nazareth et al. 2006) with minor modifications. Wistar rats were anaesthetized with sodium thiopental ( $85 \mathrm{mg} / \mathrm{kg}$, i.p.). Body temperature was monitored by a rectal thermometer and maintained at $36{ }^{\circ} \mathrm{C} \pm 1{ }^{\circ} \mathrm{C}$ using a thermal surgical table, as previously established (Bohrer et al. 2007). A laparotomy was performed, and the caudal vena cava was carefully dissected from surrounding tissues. Rats received the following treatments via the left femoral vein (final volume of $0.7 \mathrm{ml}$ was completed with PBS): (i) PBS; (ii) saliva $(0.7 \mathrm{mg} / \mathrm{kg}$ of rat body weight); (iii) saliva $(0.7 \mathrm{mg} / \mathrm{kg}$ of rat body weight) and $500 \mu \mathrm{l}$ of TNBS; or (iv) saliva $(0.7 \mathrm{mg} /$ $\mathrm{kg}$ of rat body weight) and $500 \mu \mathrm{l}$ of RIBS. After $5 \mathrm{~min}$, calcium thromboplastin $(3 \mathrm{mg} / \mathrm{kg}$ body weight) was injected in the vena cava (near to the right renal vein) and stasis was immediately established by the ligation of caudal vena cava (above the insertion point of the right renal vein). The distal ligations of the vena cava (above the common iliac veins confluence), left renal vein and other major tributaries were conducted exactly $20 \mathrm{~min}$ after thromboplastin administration. The isolated segment of the caudal vena cava was removed and carefully opened. The thrombus was separated from the isolated segment, rinsed with $0.9 \% \mathrm{NaCl}$ (at $\left.37^{\circ} \mathrm{C}\right)$ and dried on a filter paper at $60{ }^{\circ} \mathrm{C}(1 \mathrm{~h})$, and weighed. The ratio value of thrombus: rat weight was used in the comparisons. Results are the mean of 8 independent experiments.

\section{Statistical analysis}

Data are expressed as mean \pm s.E.M. of $n$ animals. Statistical significance was analysed by one-way analysis of variance (ANOVA) followed by the Bonferroni post hoc test correction. A $p$ value of less than $0 \cdot .05$ was considered significant. Statistical analysis was performed using GraphPad Prism 3.0 (GraphPad Software Inc., San Diego, USA) software.

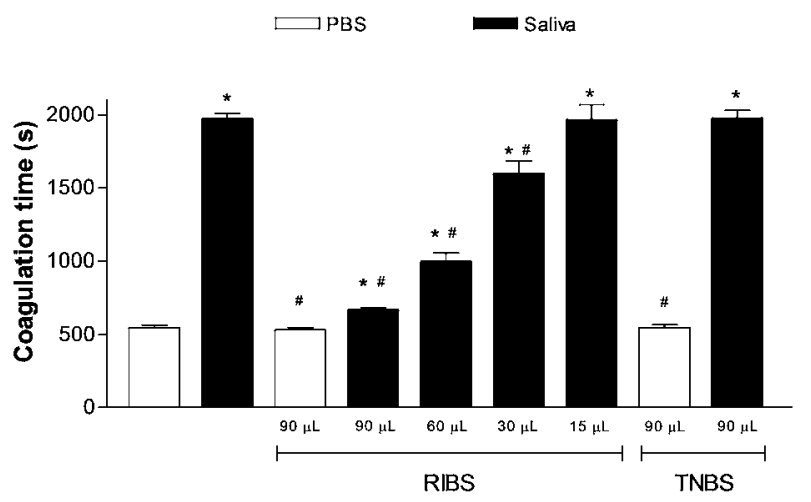

Fig. 1. Effects of repeatedly infested bovine sera (RIBS) on anti-coagulant activity of Rhipicephalus microplus saliva. The anti-coagulant action of saliva was measured by Recalcification Time (RT). The neutralization ability of sera from repeatedly infested cattle upon salivary anti-coagulation was also analysed. Saliva $(80 \mu \mathrm{g} / \mathrm{ml})$ was previously incubated with PBS, tick-naïve bovine sera (TNBS), or RIBS, as indicated, and then added to plasma samples to determine coagulation time. The volume $(\mu \mathrm{l})$ of incubated PBS, TNBS or RIBS is also indicated. (*Statistical difference compared with group PBS + plasma, \# statistical difference compared with group PBS + plasma + saliva, $P<0 \cdot 05)$.

\section{RESULTS}

\section{Coagulation}

$R$. microplus saliva significantly increased Recalcification Time (RT). When saliva $(80 \mu \mathrm{g} / \mathrm{ml})$ was pre-incubated with $100 \mu \mathrm{l}$ of bovine plasma for 15 min, RT increased by almost 4 times, as compared with the control (Fig. 1). This anti-coagulant effect was almost totally neutralized when saliva was previously incubated (for $20 \mathrm{~min}$ ) with $90 \mu \mathrm{l}$ of repeated infested bovine sera (RIBS) before addition to the plasma in the RT assay (Fig. 1). This phenomenon seems to be dose-dependent, since the ability to block the anti-coagulant effect was directly related to serum quantity in the assay (Fig. 1). Experiments performed $(n=3)$ with higher amounts of RIBS $(200 \mu \mathrm{l})$ led to the same result observed for $90 \mu \mathrm{l}$ (data not shown). In contrast, the tick-naïve bovine sera (TNBS) were not able to block the anti-coagulant effects of saliva (Fig. 1).

\section{Endothelial cell modulation}

In order to investigate whether $R$. microplus could impair haemostasis not only by inhibition of humoral factors but also by acting via endothelium, the ability of $R$. microplus saliva to negatively modulate endothelial activation was evaluated. For this purpose, a model of endothelial activation induced by LPS was employed. Cell activation was detected as a change in cell surface pro-coagulant activity. Endothelial cells (40000 cells) previously incubated for $48 \mathrm{~h}$ with 

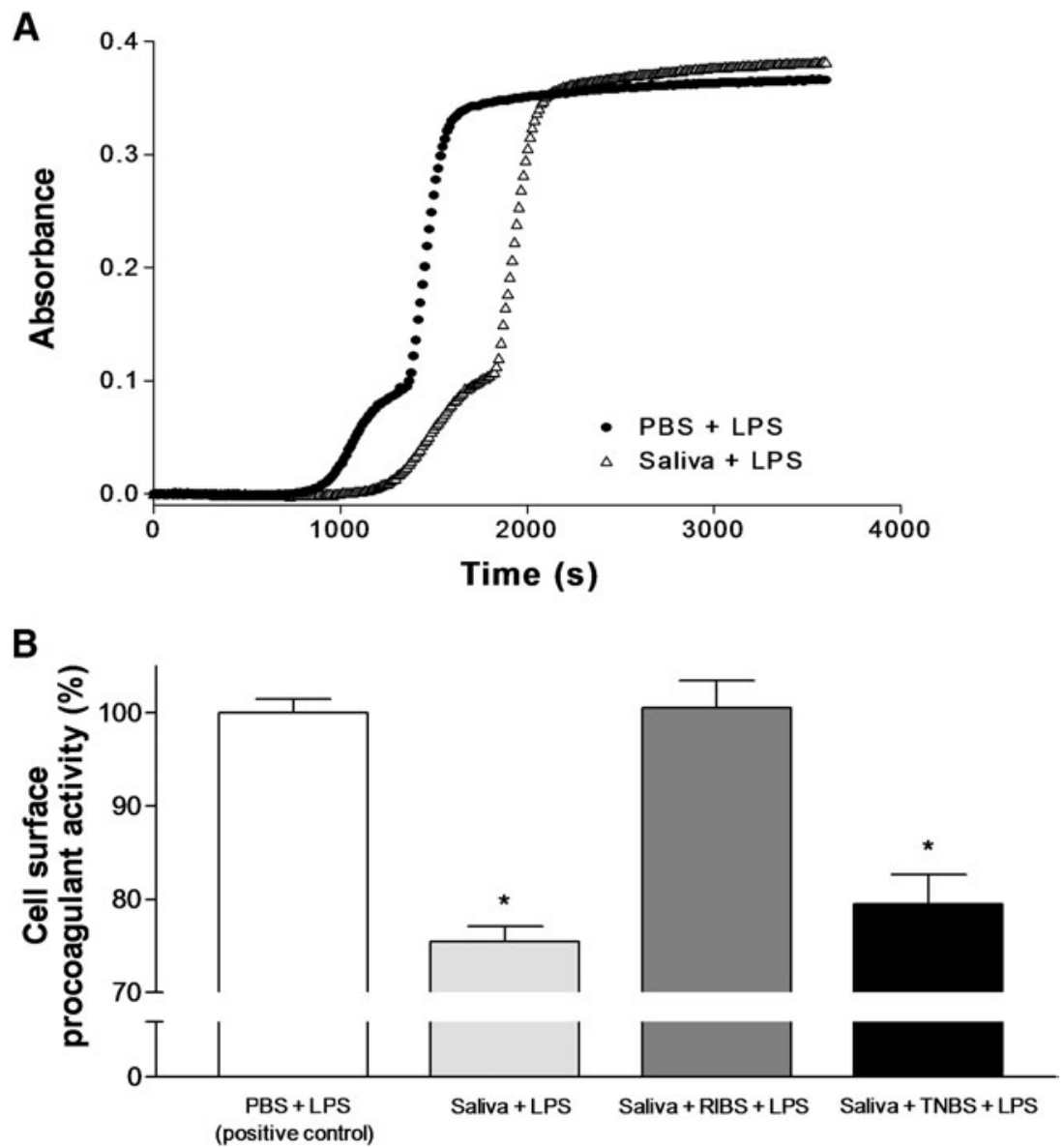

Fig. 2. Effects of Rhipicephalus microplus saliva and repeatedly infested bovine sera (RIBS)-treated saliva on the modulation of endothelial cell activation. The action of saliva on endothelial activation was analysed by cell surface-procoagulant assay. The neutralization ability of sera from repeated infested cattle upon salivary activities on endothelium was also analysed. (A) Representative register of the decrease in cellular pro-coagulant activity of EAhy926 monolayer pre-treated with saliva $(40 \mu \mathrm{g} / \mathrm{ml}, \triangle)$ compared with the control (cells pre-treated PBS, -) after endothelial activation induced by LPS $(150 \mu \mathrm{g} / \mathrm{ml})$. (B) Pro-coagulant activity of LPS-activated EAhy926 cells previously treated with PBS (positive control), saliva $(40 \mu \mathrm{g} / \mathrm{ml})+\operatorname{PBS}(25 \mu \mathrm{l})$, saliva $(40 \mu \mathrm{g} /$ $\mathrm{ml})+\operatorname{RIBS}(25 \mu \mathrm{l})$, or saliva $(40 \mu \mathrm{g} / \mathrm{ml})+$ TNBS $(25 \mu \mathrm{l})$. (*Statistical difference compared with positive control group, $P<0 \cdot 05)$.

R. microplus saliva $(40 \mu \mathrm{g} / \mathrm{ml})$ and activated with LPS $(150 \mu \mathrm{g} / \mathrm{ml}$ for $24 \mathrm{~h})$ exhibited reduced procoagulant surface activity as compared to the control (incubated with PBS) (Fig. 2A). Under the conditions used, this effect does not seem to be dose dependent, since a higher saliva concentration $(80 \mu \mathrm{g} / \mathrm{ml})$ induced the same effect as that caused by $40 \mu \mathrm{g} / \mathrm{ml}$ of saliva (data not shown). Similarly, lower saliva concentrations (10 and $20 \mu \mathrm{g} / \mathrm{ml}$ ) were not able to induce significant changes in pro-coagulant activity (data not shown). A previous incubation of $R$. microplus saliva $(40 \mu \mathrm{g} / \mathrm{ml})$ with RIBS $(50 \mu \mathrm{l})$ led to a complete blockade of endothelial modulation by saliva, since the cells displayed the same procoagulant profile of the control (previously incubated only with PBS) (Fig. 2B). Results from saliva previously incubated with the TNBS showed the same endothelial activation profile as those treated only with saliva (Fig. 2B). None of the treatments performed induced any significant differences in endothelial cell viability (data not shown).

In vivo thrombosis model

Considering that $R$. microplus saliva was able to inhibit coagulation and endothelial cell activation, these anti-haemostatic mechanisms were investigated in vivo using the rat model of deep venous thrombosis, which includes all haemostatic pathways. It was shown that $R$. microplus saliva $(0.7 \mathrm{mg} / \mathrm{kg}$ of rat body weight) is able to significantly reduce the ratio thrombus: rat weight to about $40 \%$ of the control value (Fig. 3). Moreover, pre-incubation of saliva $(0.7 \mathrm{mg} / \mathrm{kg})$ with $500 \mu \mathrm{l}$ of RIBS led to a partial reversion of anti-thrombotic activity, since the ratio thrombus/rat weight was recovered to about $80 \%$ of the control value (Fig. 3). Experiments performed $(n=3)$ with higher amounts of RIBS 


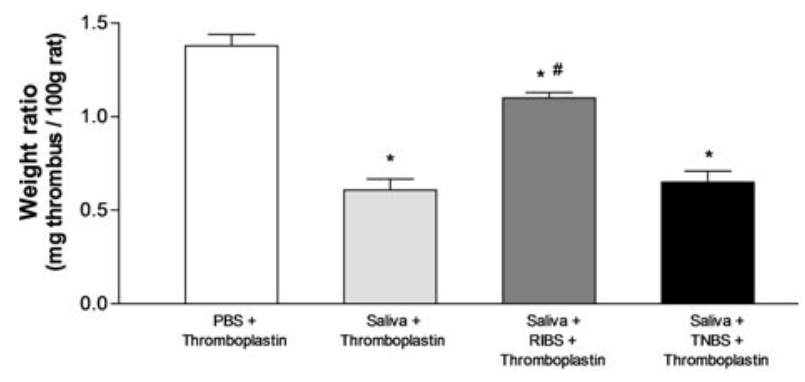

Fig. 3. Effects of Rhipicephalus microplus saliva and repeatedly infested bovine sera (RIBS)-treated saliva on thrombogenesis. The anti-thrombotic activity of saliva was measured by use of an in vivo model of rat deep venous thrombosis. The neutralization ability of sera from repeatedly infested cattle upon salivary antithrombotic action was also analysed. The treatments given to the rats were (i) PBS; (ii) saliva $(0.7 \mathrm{mg} / \mathrm{kg}$ of rat body weight) and PBS; (iii) saliva $(0.7 \mathrm{mg} / \mathrm{kg})$ and $500 \mu \mathrm{l}$ of TNBS; or (iv) saliva $(0.7 \mathrm{mg} / \mathrm{kg})$ and $500 \mu \mathrm{l}$ of RIBS. The different treatments were administered (i.v.) $5 \mathrm{~min}$ before induction of thrombosis by thromboplastin ( $3 \mathrm{mg} / \mathrm{kg}$ rat body weight) and stasis, as described in the Materials and Methods section. (*Statistical difference compared with group PBS + thromboplastin, ${ }^{\#}$ statistical difference compared with group saliva + thromboplastin, $P<0 \cdot 05)$.

(700 and $1000 \mu \mathrm{l}$ ) led to the same result as observed for $500 \mu \mathrm{l}$ (data not shown). TNBS did not reverse the anti-thrombotic action of $R$. microplus saliva (Fig. 3).

\section{Platelet aggregation}

Platelet aggregation studies were performed in an optical aggregometer using washed rabbit platelets (WRP) and thrombin, collagen, arachidonic acid and ADP as agonists. Firstly, experiments were performed in order to investigate whether $R$. microplus salivary secretion was able to inhibit platelet aggregation. For this purpose, different concentrations of saliva were incubated with WRP for $15 \mathrm{~min}$ (at $\left.37^{\circ} \mathrm{C}\right)$. Then, agonist was added and the change in absorbance was immediately recorded. No inhibition was observed for platelet aggregation induced by thrombin, arachidonic acid or ADP after preincubation of WRP with $R$. microplus saliva, even at a high saliva concentration $(420 \mu \mathrm{g} / \mathrm{ml})$ (data not shown). However, R. microplus saliva displayed inhibitory activity upon collagen-induced platelet aggregation, which was totally inhibited at the concentration of $200 \mu \mathrm{g} / \mathrm{ml}$ of saliva (Fig. 4A). This inhibition occurred in a dose-dependent fashion, with an $\mathrm{IC}_{50}$ of $53 \mu \mathrm{g} / \mathrm{ml}$ of saliva (Fig. $4 \mathrm{~B}$ ). It is interesting to note that, although RIBS induced a significant blockade of anti-coagulant, endothelium modulation and anti-thrombotic properties of R. microplus saliva, no interference in platelet aggregation inhibition induced by saliva was observed, even after incubation in the presence of high quantities of RIBS $(150 \mu \mathrm{l} / 150 \mu \mathrm{l}$ of WRP) (data not shown).

\section{DISCUSSION}

Ticks are blood-feeding animals that require mechanisms to modulate host defence against parasitism, such as vasoconstriction, haemostasis, inflammation, pain, and innate and adaptive immune responses (Maritz-Olivier et al. 2007; Francischetti et al. 2009). Despite the powerful tick evasion mechanisms, after repeated tick infestations vertebrate hosts may develop some degree of resistance to the parasite (Wikel, 1996a; Brossard and Wikel, 2004). Nevertheless, it occurs mainly in situations of repeated high parasite load. Acquired resistance to tick infestation is expressed as a decrease in engorgement weight, increased time of feeding, impaired egg production and viability, inhibition of moult as well as death of ticks (Wikel, 1982, 1996b). Although the host-tick relationship is one of the most extensively studied host-parasite associations, the knowledge about host reactivity, tick resistance and saliva modulators is not enough to afford a complete understanding of this process.

In this work, anti-haemostatic mechanisms of $R$. microplus saliva and the humoral response within anti-tick natural acquired resistance were investigated. According to a previous report (Horn et al. 2000 ), it was shown that $R$. microplus saliva was able to induce a significant increase (about 4 times) in plasma coagulation time measured in the RT assay. This saliva activity was imputed to the action of the thrombin inhibitors, BmAP (Horn et al. 2000) and microphilin (Ciprandi et al. 2006). Figure 1 shows that repeatedly infested bovine sera (RIBS) were able to significantly decrease the anti-coagulant effects of saliva in a dose-dependent fashion. Although there was a marked reduction in the saliva effect, a complete reversion of anti-coagulant effect was not observed. The blockade of salivary anti-coagulant activity clearly indicates that there are neutralizing molecules in RIBS, not present in TNBS, acting upon the salivary anti-coagulants, probably antibodies, since these anti-coagulants are secreted in the saliva and inoculated into the host. Analogously, a study by Prevot and co-workers (2007) reported the ability of repeatedly infested rabbit serum to neutralize the enzymatic inhibitory activity of Ixodes ricinus salivary serpin. This kind of serum neutralization assay, although frequently reported against biological action of microbial diseases (Rutter et al. 1975 ; Johnson et al. 1995), was poorly reported for ectoparasites.

Although the effects of $R$. microplus saliva upon coagulation are well known (Horn et al. 2000; Ciprandi et al. 2006), other possible anti-haemostatic mechanisms have not yet been fully characterized, 


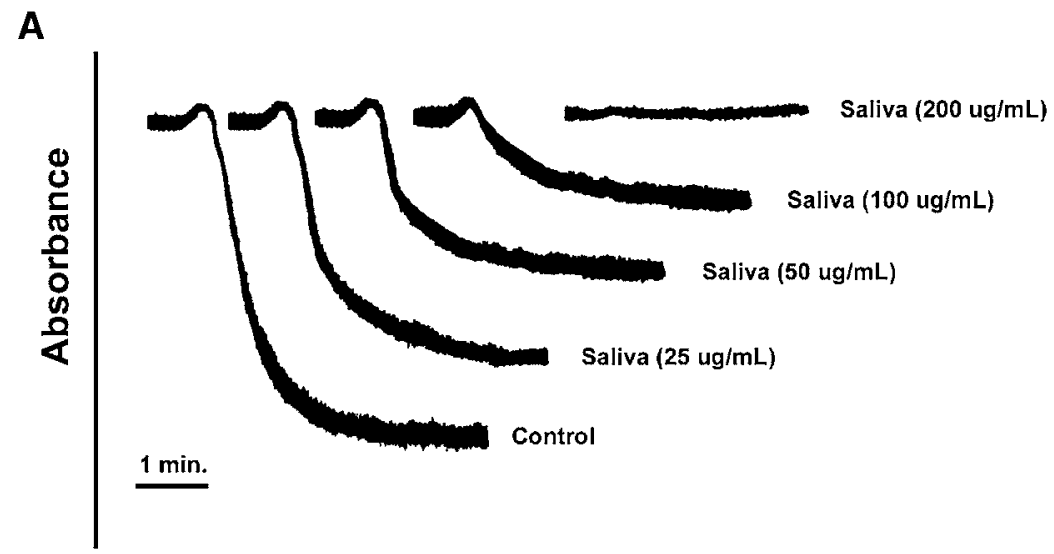

B

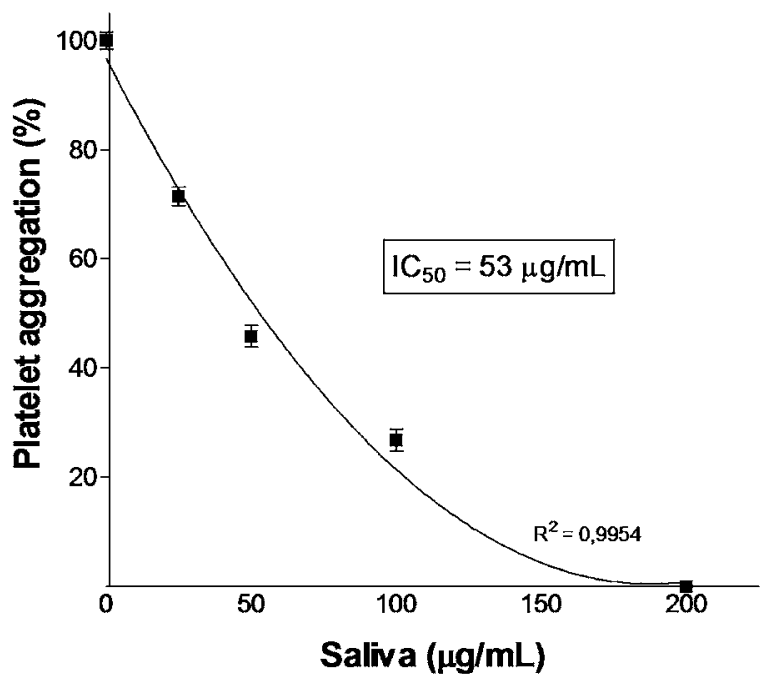

Fig. 4. Effects of Rhipicephalus microplus saliva on collagen-induced platelet aggregation. The inhibitory activity of crescent concentrations of $R$. microplus saliva $(25,50,100$ or $200 \mu \mathrm{g} / \mathrm{ml})$ upon WRP aggregation induced by collagen ( $3 \mu \mathrm{M})$ was measured. (A) Representative profile of collagen induced-platelet aggregation of WRP previously incubated with R. microplus saliva. (B) Each point represents the mean from 6 independent experiments, and vertical lines indicate the S.E.M.

leaving significant gaps concerning the role saliva molecules play in other haemostatic events, such as platelet aggregation, endothelial response, and thrombogenesis. The data presented here clearly show that $R$. microplus saliva exerts a significant effect upon the endothelium. Figure 2A demonstrates that saliva is able to reduce the endothelial procoagulant activity induced by LPS due to a direct effect of saliva upon endothelial cells, probably via an alteration in protein surface composition and/or induced gene expression (Makrides and Ryan, 1998). Endothelial activation is a complex process which includes a reversion in the cell phenotype, changing from an anti-thrombotic state to a pro-thrombotic state in response to several stimuli, like cellular lesion, bacterial and viral infection, peptide signalling, or chemical damage (Gibbons, 1998). Modulation of endothelial cells by tick saliva seems to be an alternative pathway to control host defences independently of humoral mechanisms, which could allow the parasite to regulate haemostasis, inflammation, immunity and lesion cicatrization. Maxwell and coworkers (2005) have demonstrated that salivary gland extracts of Dermacentor andersoni significantly down-regulated the expression of inflammatory molecules, such as ICAM-1. They have also reported that salivary gland extracts of $I$. scapularis reduced the expression of different adhesion-molecules, such as selectins and VCAM-1. Francischetti and co-workers (2005) have reported the potent antiangiogenic and anti-proliferative activities of $I$. scapularis saliva upon endothelial cells, introducing the novel notion that tick saliva is a negative modulator of wound healing and tissue repair. Despite these two very elegant reports about tick saliva and salivary gland action on the biology of endothelial cells, the modulation of the haemostatic properties of the endothelium by ticks has never been reported before. A lingering doubt surrounds the ability of other ticks, specially two and three host-ticks, to modulate the haemostatic properties of the endothelium in a similar fashion. 
It is interesting to note that when saliva was preincubated with RIBS, the salivary modulatory effects upon endothelium were totally blocked, differently from that which occurs with coagulation, where the serum blocking effect was only partial. Thus, host neutralization ability seems to be more powerful for the salivary molecules responsible for the modulation of endothelium than for coagulation. Despite the fact that cell modulation by ticks is possibly triggered by several molecules with synergistic action - or by a cocktail of compounds (Wikel et al. 1996) - it seems that infestation induces the production of different neutralizing antibodies able to block this seemingly multifactorial effect.

The occurrence of haemostatic disturbances in tick-infested calves indicates that $R$. microplus saliva is able to modulate haemostasis in vivo (Reck Jr et al. 2009), and it strongly suggests the presence of in vivo anti-thrombotic activity. In order to evaluate the anti-haemostatic properties of saliva in a model that reproduces all pathways involved in haemostasis, we investigated the anti-thrombotic ability of tick saliva using the in vivo model of rat deep venous thrombosis. Although other ticks display salivary anti-thrombotic properties (Fioravanti et al. 1993; Nazareth et al. 2006) and despite the fact that the in vitro anti-coagulant effects of $R$. microplus saliva are well known, the anti-thrombotic activity of $R$. microplus saliva has never been reported before. Here we have shown that $R$. microplus saliva clearly modulates thrombogenesis, and that RIBS were able to induce a significant decrease in saliva antithrombotic activity. This reduction, however, does not promote a complete recovery of the thrombotic activity, since the group treated with RIBS significantly differs in comparison with both the control group (treated only with thromboplastin) and the saliva-treated group. The residual anti-thrombotic activity of saliva was probably due to the fact that RIBS neutralization activity seems to be different in the three haemostatic pathways studied here, since RIBS are able to totally neutralize the action of tick saliva upon endothelium and to nearly block the effect of salivary anti-coagulant, although it has no neutralizing activity upon platelet aggregation inhibition. Taking into account the variety of compounds that participate in the thrombogenesis in vivo, the anti-thrombotic effect exerted by $R$. microplus saliva probably implies a wide arsenal of molecules that, as regards immune evasion mechanisms, tend to avoid the recognition of the epitopes necessary to completely neutralize the overall effect. In fact, a full blockage of all activities involved in anti-thrombosis would probably result in suppression of blood feeding. But in fact this does not occur, since some ticks remain attached to the resistant host and succeed to complete their parasitic cycle, though with a marked reduction in number and viability of parasites (Wikel, 1982; Cruz et al. 2008).
Since several ticks and other haematophagous arthropods display platelet antagonists as one of their anti-haemostatic resources, the occurrence of platelet aggregation inhibitors in $R$. microplus was investigated. The present study reports, for the first time, that $R$. microplus saliva is able to inhibit the collagen-induced platelet aggregation in WRP. This inhibition could be related to the collagen-binding component reported in the salivary glands of $R$. $m i$ croplus (Ferreira et al. 2002). Collagen-induced platelet aggregation may occur through two distinct pathways, directly via activation of phospholipase $\mathrm{C}$ or via arachidonic acid pathway or indirectly via ADP release from cell granules. The fact that $R$. microplus saliva does not inhibit arachidonic acidinduced platelet aggregation indicates this tick uses a distinct mechanism to inhibit collagen-induced platelet aggregation, as compared to Ornithodoros moubata (Mans and Ribeiro, 2008). Surprisingly, no saliva inhibition was observed in platelet response to thrombin, arachidonic acid or ADP (data not shown), in spite of the fact that $R$. microplus possesses two thrombin inhibitors in saliva. The lack of inhibition in thrombin-induced platelet aggregation could be due to an insufficient concentration reached by the salivary thrombin inhibitors in the saliva preparations utilized, leading to an unfeasible inhibition only because the inhibitor concentration is not high enough to suppress thrombin activity. This hypothesis is corroborated by comparing the saliva concentration used in the experiment with the $\mathrm{Ki}$ of microphilin, which is in the micromolar range (Ciprandi et al. 2006). Indeed, this result seems to contradict a previous report, since microphilin, an $R$. microplus thrombin inhibitor, inhibits fibrinocoagulation and thrombin-induced platelet aggregation (Ciprandi et al. 2006). However, besides microphilin $\mathrm{Ki}$, this contrasting finding could be explained by analytical differences between the studies, since we performed the incubation of saliva with the platelets and added the agonist after a time interval (thrombin, collagen, arachidonic acid or ADP), while Ciprandi and co-workers (2006) performed the incubation of saliva with thrombin and added the mixture to platelets after a time interval. The approach employed by Ciprandi and co-workers (2006) was designed to characterize the effects of thrombin inhibition by microphilin binding.

It is interesting to note that among all activities investigated, the inhibition of platelet aggregation is the only one in which the RIBS used were not able to interfere (data not shown), which suggests that the salivary anti-platelet molecule(s) has (have) low immunogenicity and is probably due to the naturally acquired resistance to ticks in the bovines used. However, this does not imply that the platelet aggregation inhibitor should be dismissed as an unfeasible resource for the development of an anti-tick vaccine. In this sense, Kotsyfakis and co-workers 
(2008) conducted an efficient study that introduced a new concept in the tick-host relationship-the silent antigens-like sialostatin L2. This molecule was found in I. scapularis saliva and was not recognized by sera of guinea pigs repeatedly exposed to ticks; yet, when sialostatin L2 was used as a vaccine antigen, the serum of vaccinated animals recognized the protein and the immunization procedure lent protection to the hosts (Kotsyfakis et al. 2008).

Despite the widely accepted notion that tick saliva is largely non-immunogenic, our study suggests that anti-coagulants, endothelial modulators and antithrombotic molecules are immunogenic and could be used as vaccinal antigens to reproduce the resistance status of repeatedly infested bovines, which would be accomplished through a vaccination strategy, and possibly reinforced by natural infestations. However, our results were obtained with non-diluted sera, indicating that this immunogenicity is not as high as that obtained by highly immunogenic antigens, as concealed antigens. Accordingly, our data indicate that the molecules involved in anti-haemostasis may be candidates to compose a cocktail vaccine, possibly in a strategy associating concealed and silent antigens.

Studies evaluating the relative importance of an adaptative humoral response in bovine resistance against $R$. microplus presented conflicting results. The levels of anti- $R$. microplus antibodies were not positively correlated with resistance in some analyses (Johnston et al. 1986; Kimaro and Opdebeeck, 1994; Jackson and Opdebeeck, 1995), but were positively correlated in others, either originated from vaccination (Willadsen, 1987; Willadsen et al. 1995) or repeated infestations (Cruz et al. 2008). Here we show that sera from resistant bovines, although presenting low titres of anti-tick antibodies (Cruz et al. 2008), were able to impair anti-haemostatic tick saliva activities. These results suggest that global levels of anti-tick antibodies are not undoubtedly indicative of host resistance. Since levels of antibodies are modulated by tick infestation (Cruz et al. 2008), antibodies induced by high-density infestations could be predominantly targeted to unessential and/or a fraction of functionally redundant molecules.

Although the biochemical and immunological basis of anti-haemostatic mechanisms of ticks (Ribeiro, 1995; Ribeiro and Francischetti, 2003; Maritz-Olivier et al. 2007; Francischetti et al. 2009) and the natural acquired resistance (Wikel, $1996 a, b$ ) have been widely studied, reports concerning the possible relationship between these two phenomena are scarce. The present work shows, for the first time, the occurrence of neutralizing activity against the salivary anti-haemostatics of ticks in sera of repeatedly infested hosts that exhibit natural acquired resistance. Also, this study is the first to report a haematophagous parasite modulating the endothelial cell pro-coagulant state, and shows the presence of platelet aggregation inhibitory and anti-thrombotic action in $R$. microplus saliva.

Finally, since acquired resistance and successful parasitism seem to depend on a state of balance between host defences and tick modulators (Wikel, 1996a), this study allows a better understanding of the relationship between the acquired natural tick resistance and the anti-haemostatic action and gives more insights to elucidate mechanisms related with the tick-host interaction.

We are indebted to the Conselho Nacional de Pesquisa $(\mathrm{CNPq})$, Fundação de Amparo à Pesquisa do Estado do Rio Grande do Sul (FAPERGS) and Coordenação de Aperfeiçoamento de Pessoal de Nível Superior (CAPES) for financial support. Special thanks to Dr Lucélia Santi, Dr Renata Terra and Dr Antônio Pinto (Centro de Biotecnologia, UFRGS) for their assistance in the execution of this work, to Ana Cruz (PUCRS) and Professor Sérgio Silva (Faculdade de Veterinária, UFPel) for kindly providing of cattle serum samples, to Professor Fabiana Horn (Departamento de Biofísica, UFRGS) for critical review of this manuscript and for kindly providing endothelial cells, and to Dr Cora-Jean Edgell (Department of Pathology, University of North Carolina) for the permission to use EAhy926 cells.

\section{REFERENCES}

Allen, J. R. (1994). Host resistance to ectoparasites. Revue Scientifique et Technique - Office International des Epizooties 13, 1287-1303.

Berger, M., Pinto, A. F. and Guimarães, J. A. (2008). Purification and functional characterization of bothrojaractivase, a prothrombin-activating metalloproteinase isolated from Bothrops jararaca snake venom. Toxicon 51, 488-501.

Bohrer, C. B., Reck, J. J., Fernandes, D., Sordi, R., Guimarães, J. A., Assreuy, J. and Termignoni, C. (2007). Kallikrein kinin system activation by Lonomia obliqua caterpillar bristles: Involvement in edema and hypotension responses to envenomation. Toxicon 49, 663-669.

Born, G. V. R. and Cross, M. J. (1963). The aggregation of blood platelets. Fournal of Physiology 168, 178-195.

Brossard, M. and Wikel, S. K. (2004). Tick immunobiology. Parasitology 129 (Suppl.), S161-S176.

Brown, R. E. (1989). Protein measurement using bicinchoninic acid: elimination of interfering substances. Analytical Biochemistry 180, 136-139.

Champagne, D. E. and Valenzuela, J. G. (1996). Pharmacology of haematophagous arthropod saliva. In The Immunology of Host-Ectoparasitic Arthropod Relationships (ed. Wikel, S. K.), pp. 85-106. CAB International, Wallingford, UK.

Ciprandi, A., Oliveira, S. K., Masuda, A., Horn, F. and Termignoni, C. (2006). Boophilus microplus: its saliva contains microphilin, a small thrombin inhibitor. Experimental Parasitology 114, 40-46.

Cruz, A. P., Silva, S. S., Mattos, R. T., Da Silva Vaz, I., Jr., Masuda, A. and Ferreira, C. A. (2008).

Comparative $\mathrm{IgG}$ recognition of tick extracts by sera of experimentally infested bovines. Veterinary Parasitology 158, 152-158. 
Déruaz, M., Frauenschuh, A., Alessandri, A. L., Dias, J. M., Coelho, F. M., Russo, R. C., Ferreira, B. R., Graham, G. J., Shaw, J. P., Wells, T. N., Teixeira, M. M., Power, C. A. and Proudfoot, A. E. (2008). Ticks produce highly selective chemokine binding proteins with anti-inflammatory activity. Fournal of Experimental Medicine 205, 2019-2031.

Dickinson, R. G., O’Hagan, J. E., Schotz, M., Binnington, K. C. and Hegarty, M. P. (1976). Prostaglandin in the saliva of the cattle tick Boophilus microplus. The Australian Fournal of Experimental Biology and Medical Science 54, 475-486.

Edgell, C. J., McDonald, C. C. and Graham, J. B. (1983). Permanent cell line expressing human factor VIII-related antigen established by hybridization. Proceedings of the National Academy of Sciences, USA 80, 3734-3737.

FASS. (1999). Guide for the Care and Use of Agricultural Animals in Agricultural Research and Teaching. 1st Edn. ,Federation of Animal Science Societies, Savoy, USA.

Ferreira, C. A., Da Silva Vaz, I., Silva, S. S., Haag, K. L., Valenzuela, J. G. and Masuda, A. (2002). Cloning and partial characterization of a Boophilus microplus (Acari: Ixodidae) calreticulin. Experimental Parasitology 101, 25-34.

Francischetti, I. M., Valenzuela, J. G., Andersen, J. F., Mather, T. N. and Ribeiro, J. M. (2002). Ixolaris, a novel recombinant tissue factor pathway inhibitor (TFPI) from the salivary gland of the tick, Ixodes scapularis: identification of factor $\mathrm{X}$ and factor $\mathrm{Xa}$ as scaffolds for the inhibition of factor $\mathrm{VIIa}$ /tissue factor complex. Blood 99, 3602-3612.

Francischetti, I. M., Mather, T. N. and Ribeiro, J. M. (2004). Penthalaris, a novel recombinant five-Kunitz tissue factor pathway inhibitor (TFPI) from the salivary gland of the tick vector of Lyme disease, Ixodes scapularis. Thrombosis and Haemostasis 91, 886-898.

Francischetti, I. M. B., Mather, T. N. and Ribeiro, J. M. C. (2005). Tick saliva is a potent inhibitor of endothelial cell proliferation and angiogenesis. Thrombosis and Haemostasis 94, 167-174.

Francischetti, I. M., Sa-Nunes, A., Mans, B. J., Santos, I. M. and Ribeiro, J. M. (2009). The role of saliva in tick feeding. Frontiers in Bioscience 14, 2051-2088.

Fioravanti, C., Burkholder, D., Francis, B., Sieg1, P. K. and Gibson, R. E. (1993). Antithrombotic activity of recombinant tick anticoagulant peptide and heparin in a rabbit model of venous thrombosis. Thrombosis Research 71, 317-324.

Gibbons, G. H. (1998). The vascular response to injury. In Thrombosis and Hemorrhage (ed. Loscalzo, J. and Schafer, A. I.), pp. 307-320, 2nd Edn. Williams \& Wilkins, Baltimore, MD, USA.

Guimarães, J. H., Tucci, E. C. and Barros-Battesti, D. M. (2001). Ectoparasitos de Importância Veterinária. 1 st Edn. Editora Plêiade, São Paulo, Brazil.

Horn, F., Santos, P. C. and Termignoni, C. (2000). Boophilus microplus anticoagulant protein: an antithrombin inhibitor isolated from the cattle tick saliva. Archives of Biochemistry and Biophysics $\mathbf{3 8 4}$ 68-73.

Jackson, L. A. and Opdebeeck, J. P. (1995). The effect of various adjuvants on the humoral immune response of sheep and cattle to soluble and membrane midgut antigens of Boophilus microplus. Veterinary Parasitology 58, 129-141.

Johnson, S., Sypura, W. D., Gerding, D. N., Ewing, S. L. and Janoff, E. N. (1995). Selective neutralization of a bacterial enterotoxin by serum immunoglobulin A in response to mucosal disease. Infection and Immunity $\mathbf{6 3}$, 3166-3173.

Johnston, L. A., Kemp, D. H. and Pearson, R. D. (1986). Immunization of cattle against Boophilus microplus using extracts derived from adult female ticks: effects of induced immunity on tick populations. International Fournal for Parasitology 16, 27-34.

Jongejan, F. and Uilenberg, G. (2004). The global importance of ticks. Parasitology 129 (Suppl.), S3-S14.

Juncadella, I. J., Garg, R., Ananthnarayanan, S. K., Yengo, C. M. and Anguita, J. (2007). T-cell signaling pathways inhibited by the tick saliva immunosuppressor, Salp15. FEMS Immunology and Medical Microbiology 49, 433-438.

Kemp, D. H., Hales, J. R., Schleger, A. V. and Fawcett, A. A. (1983). Comparison of cutaneous hyperemia in cattle elicited by larvae of Boophilus microplus and by prostaglandins and other mediators. Experientia 39, 725-727.

Kimaro, E. E. and Opdebeeck, J. P. (1994). Tick infestations on cattle vaccinated with extracts from the eggs and the gut of Boophilus microplus. Veterinary Parasitology 52, 61-70.

Konnai, S., Nakajima, C., Imamura, S., Yamada, S., Nishikado, H., Kodama, M., Onuma, M. and Ohashi, K. (2009). Suppression of cell proliferation and cytokine expression by HL-p36, a tick salivary glandderived protein of Haemaphysalis longicornis. Immunology 126, 209-219.

Kotsyfakis, M., Anderson, J. M., Andersen, J. F., Calvo, E., Francischetti, I. M., Mather, T. N., Valenzuela, J. G. and Ribeiro, J. M. (2008). Cutting edge: Immunity against a "silent" salivary antigen of the Lyme vector Ixodes scapularis impairs its ability to feed. Fournal of Immunology 181, 5209-5212.

Kotsyfakis, M., Sá-Nunes, A., Francischetti, I. M., Mather, T. N., Andersen, J. F. and Ribeiro, J. M. (2006). Antiinflammatory and immunosuppressive activity of sialostatin L, a salivary cystatin from the tick Ixodes scapularis. Fournal of Biological Chemistry 281, 26298-26307.

Makrides, S. C. and Ryan, U. S. (1998). Overview of the endothelium. In Thrombosis and Hemorrhage (ed. Loscalzo, J. and Schafer, A. I.), pp. 295-306, 2nd Edn. Williams \& Wilkins, Baltimore, MD, USA.

Mans, B. J., Gaspar, A. R., Louw, A. I. and Neitz, A. W. (1998). Purification and characterization of apyrase from the tick, Ornithodoros savignyi. Comparative Biochemistry and Physiology B - Biochemistry and Molecular Biology 120, 617-624.

Mans, B. J., Louw, A. I. and Neitz, A. W. (2002). Savignygrin, a platelet aggregation inhibitor from the soft tick Ornithodoros savignyi, presents the RGD integrin recognition motif on the Kunitz-BPTI fold. Fournal of Biological Chemistry 277, 21371-21378.

Mans, B. J. and Ribeiro, J. M. (2008). Function, mechanism and evolution of the moubatin-clade of soft tick lipocalins. Insect Biochemistry and Molecular Biology 38, 841-852. 
Maritz-Olivier, C., Stutzer, C., Jongejan, F., Neitz, A. W. and Gaspar, A. R. (2007). Tick anti-hemostatics: targets for future vaccines and therapeutics. Trends in Parasitology 23, 397-407.

Maxwell, S. S., Stoklasek, T. A., Dash, Y., Macaluso, K. R. and Wikel, S. K. (2005). Tick modulation of the in-vitro expression of adhesion molecules by skinderived endothelial cells. Annals of Tropical Medicine and Parasitology 99, 661-672.

Murrell, A. and Barker, S. C. (2003). Synonymy of Boophilus Curtice, 1891 with Rhipicephalus Koch, 1844 (Acari: Ixodidae). Systematic Parasitology 56, 169-172.

Nazareth, R. A., Tomaz, L. S., Ortiz-Costa, S., Atella, G. C., Ribeiro, J. M., Francischetti, I. M. and Monteiro, R. Q. (2006). Antithrombotic properties of Ixolaris, a potent inhibitor of the extrinsic pathway of the coagulation cascade. Thrombosis and Haemostasis 96, 7-13.

Ngai, P. K. and Chang, J. Y. (1991). A novel one-step purification of human alpha-thrombin after direct activation of crude prothrombin enriched from plasma. The Biochemical Yournal 280, 805-808.

Prevot, P. P., Couvreur, B., Denis, V., Brossard, M., Vanhamme, L. and Godfroid, E. (2007). Protective immunity against Ixodes ricinus induced by a salivary serpin. Vaccine 25, 3284-3292.

Reck, J., Jr., Berger, M., Terra, R. M. S., Marks, F. S., da Silva Vaz, I., Jr., Guimarães, J. A. and Termignoni, C. (2009). Effects of the tick Rhipicephalus (Boophilus) microplus infestation on the host hemostatic system. Research in Veterinary Science 86, 56-62.

Ribeiro, J. M. (1989). Role of saliva in tick/host interaction. Experimental and Applied Acarology 7, 15-20.

Ribeiro, J. M. (1995). Blood-feeding arthropods: live syringes or invertebrate pharmacologists? Infectious Agents and Diseases 4, 143-152.

Ribeiro, J. M. and Francischetti, I. M. B. (2003). Role of arthropod saliva in blood-feeding: sialome and post-sialome perspectives. Annual Review of Entomology 48, 73-88.

Ribeiro, J. M., Schneider, M. and Guimarães, J. A. (1995). Purification and characterization of prolixin S (nitrophorin 2), the salivary anticoagulant of blood-sucking bug Rhodnius prolixus. The Biochemical Fournal 308, 243-249.

Ricci, C. G., Pinto, A. F. M., Berger, M. and Termignoni, C. (2007). A thrombin inhibitor from the gut of Boophilus microplus ticks. Experimental and Applied Acarology 42, 291-300.
Rutter, J. M., Jones, G. W., Brown, G. T., Burrows, M. R. and Luther, P. D. (1975). Antibacterial activity in colostrum and milk associated with protection of piglets against enteric disease caused by K88-positive Escherichia coli. Infection and Immunity 13, 667-676.

Simmonds, R. E. and Lane, D. A. (1998). Regulation of coagulation. In: Thrombosis and Hemorrhage (ed. Loscalzo, J. and Schafer, A. I.), pp. 45-76, 2nd Edn. Williams \& Wilkins, Baltimore, MD, USA.

Steeves, E. B. and Allen, J. R. (1991). Tick resistance in mast cell-deficient mice: histological studies. International Fournal for Parasitology 21, 265-268.

Timmons, S. and Hawiger, J. (1989). Isolation of human platelets by albumin gradient and gel filtration. Methods in Enzymology 169, 11-21.

Visseren, F. L., Bouwman, J. J., Bouter, K. P., Diepersloot, R. J., de Groot, P. H. and Erkelens, D. W. (2000). Procoagulant activity of endothelial cells after infection with respiratory viruses. Thrombosis and Haemostasis 84, 319-324.

Vogel, G. M., Meuleman, D. G., Bourgondiën, F. G. and Hobbelen, P. M. (1989). Comparison of two experimental thrombosis models in rats: effects of four glycosaminoglycans. Thrombosis Research 54, 399-410.

Walker, D. H. (1998). Tick-transmitted infectious diseases in the United States. Annual Review of Public Health 19, 237-269.

Wikel, S. K. (1982). Immune responses to arthropods and theirs products. Annual Review of Entomology 27, 21-48.

Wikel, S. K. (1996a). Immunology of the tick-host interface. In The Immunology of Host-Ectoparasitic Arthropod Relationships (ed. Wikel, S. K.), pp. 204-231. CAB International, Wallingford, UK.

Wikel, S. K. (1996b). Host immunity to ticks. Annual Review of Entomology 41, 1-22.

Wikel, S. K., Ramachandra, R. N. and Bergman, D. K. (1996). Arthropod modulation of host immune responses. In The Immunology of Host-Ectoparasitic Arthropod Relationships (ed. Wikel, S. K.), pp. 107-130. CAB International, Wallingford, UK.

Wikel, S. K. and Whelen, A. C. (1986). Ixodid-host immune interaction. Identification and characterization of relevant antigens and tick-induced host immunosuppression. Veterinary Parasitology 20, 149-174.

Willadsen, P. (1987). Immunological approaches to the control of ticks. International Fournal for Parasitology 17, 671-677.

Willadsen, P., Bird, P., Cobon, G. S. and Hungerford, J. (1995). Commercialization of a recombinant vaccine against Boophilus microplus. Parasitology 110 (Suppl.), S43-S50. 